\title{
First Responder Safety in the Event of a Dirty Bomb Detonation in Urban Environment
}

\author{
Sergio Biancotto $^{1 *}$, Andrea Malizia ${ }^{2}$, Gian Marco Contessa ${ }^{3}$, Marco D’Arienzo $^{3}$, Mauro Mattavelli Solbiati $^{4}$ \\ ${ }^{1}$ Independent Consultant, Turin, Italy \\ ${ }^{2}$ Department of Biomedicine and Prevention, University of Rome Tor Vergata, Rome 00133, Italy \\ ${ }^{3}$ National Agency for New Technologies, Energy and Sustainable Economic Development (ENEA), Frascati (RM) 00044, \\ Italy \\ ${ }^{4}$ Italian Fire Brigade, Expert CBRNe Team Leader Coordinator, Milan 20100, Italy
}

Corresponding Author Email: sergio.bsbs@kataail.com

https://doi.org/10.18280/ijsse.110410

Received: 10 January 2021

Accepted: 16 July 2021

\section{Keywords:}

dirty bomb, radiological dispersal device, CBRNe, terrorist attack, urban environment, total effective dose, first responders

\begin{abstract}
The malevolent dispersion of radioactive material, with the aim of contaminating people and the environment, is considered a credible terroristic threat. This article analyzes a hypothetical Dirty Bomb detonation in an urban area, estimating the radiological consequences to the involved population and to first responders. The dispersion of radioactive material is simulated using the HOTSPOT code, considering the explosion of devices containing (alternatively) ${ }^{60} \mathrm{Co},{ }^{137} \mathrm{Cs},{ }^{192} \mathrm{Ir},{ }^{238} \mathrm{Pu}$ or ${ }^{241} \mathrm{Am}$ sources, frequently used in medical or industrial settings. Each source is evaluated separately. The resulting ground deposition is used to calculate the effective dose received by first responders in two different scenarios. Based on the dispersed radionuclide, the influence of the use of personal protective respirators is analyzed. Confirming previous published results, this article illustrates that the radioactive material is diluted by the detonation, resulting in relatively low doses to the general public. However, the emergency workers' stay time in the most contaminated area must be carefully planned, in order to limit the received dose. Due to the general fear of radiation, extensive psychological effects are expected in the public, irrespective of the evaluated radiation dose.
\end{abstract}

\section{INTRODUCTION}

The continuing menace of striking terroristic actions suggests the possibility of attacks using nuclear or radioactive material, aimed at endangering people and the environment [1]. It can be hypothesized the use of a Radiological Dispersal Device (RDD), assembled using high activity sources as those frequently found in the radiotherapy and nuclear medicine departments of hospitals, in industrial settings or in research facilities all over the world. In most cases, sources are correctly and safely stored, but it is impossible to exclude their diversion for malevolent purposes, or their origin from less controlled activities. The design and the level of complexity of such a device can be only postulated, but the combination of radioactive material and conventional explosives has received the greatest attention, being popularly known as "dirty bomb" $[2,3]$. The making of a dirty bomb appears to be a relatively simple process and does not require special purpose components or difficult assembly, adding the consideration that no safety rules are required. Other than the immediate physical consequences of the explosion, the radioactive material can expose people to variable levels of radiation, and it can contaminate large areas, causing the disruption of local activities and important social effects, enhanced by the general fear of radiation $[4,5]$. In such an event, the intervention of first responders and the necessity of clean-up activities must be carefully planned, in order to avoid high doses to emergency workers [6-8].

The present study evaluates the radiological consequences of a possible dirty bomb detonation in an urban area, and it calculates the dose received by the exposed population and the resulting ground deposition. According to the contamination, it is evaluated the dose received by first responders or emergency workers in two different scenarios, resembling realistic operational activities as planned by a Fire Brigade.

Except if differently stated, the dose is presented in terms of Total Effective Dose (TED), i.e. the sum of the effective dose from external irradiation and the committed effective dose due to internal contamination caused by inhalation. The S.I. unit is the sievert $(\mathrm{Sv})$.

\section{MATERIALS AND METHODS}

Several computer code simulations are performed using the HOTSPOT program [9]. The initial evaluations are performed to assess the dose received by the population (considering a total exposure duration of 4 days) and to assess the resulting surface contamination. Each simulation considers only one radionuclide: ${ }^{60} \mathrm{Co},{ }^{137} \mathrm{Cs},{ }^{192} \mathrm{Ir},{ }^{238} \mathrm{Pu}$ or ${ }^{241} \mathrm{Am}$, alternatively.

In the second step, it is evaluated the TED received by first responders intervening one hour after the detonation. In this respect, emergency people are not affected by the plume passage, but their level of dose is determined by external exposure due to "Ground Shine" and by inhalation following "Resuspension" of deposited particles. Two realistic scenarios are evaluated, considering the time spent in different locations at various distances from the blast. Two levels of TED are 
analyzed: $1 \mathrm{mSv}$, recommended by the International Commission on Radiological Protection (ICRP) as the annual limit for the population, and $20 \mathrm{mSv}$, recommended by the ICRP as the annual limit for radiation workers [10]. When the population is concerned, the $1 \mathrm{mSv}$ value, calculated according to an exposure time equal to 4 days, can be useful in planning protective actions.

\subsection{Radionuclides}

The number of conceivable radionuclides is very large, and it is not possible to predict which one is suitable for a terroristic attack [11]. In fact, it depends on many factors such as availability, opportunity to steal and manage, easiness to transport, and many other reasons. However, the present study considers radionuclides frequently used in medical and industrial applications, representing attractive sources for a dirty bomb, due to their high specific activity and radiotoxicity: ${ }^{60} \mathrm{Co},{ }^{137} \mathrm{Cs},{ }^{192} \mathrm{Ir},{ }^{238} \mathrm{Pu},{ }^{241} \mathrm{Am}[12]$. For each radionuclide, the activity taken into account is reputed a typical activity in the medical or industrial practice, despite several exceptions exist [13]. Teletherapy makes use of ${ }^{60} \mathrm{Co}$ or ${ }^{137} \mathrm{Cs}$ sources, mainly with activity equal to $1.5 \cdot 10^{14} \mathrm{~Bq}$ and $1.9 \cdot 10^{13} \mathrm{~Bq}$, respectively. A frequently used source for industrial radiography is ${ }^{192} \mathrm{Ir}$, with a typical activity of $3.7 \cdot 10^{12} \mathrm{~Bq}\left({ }^{60} \mathrm{Co}\right.$ and ${ }^{137} \mathrm{Cs}$ are also frequently used for the same application, but at lower activity than in teletherapy). Radioisotope Thermoelectric Generators (RTGs) have a typical ${ }^{238} \mathrm{Pu}$ activity of $1.0 \cdot 10^{13} \mathrm{~Bq}$. Used for smoke detectors in the past, ${ }^{241} \mathrm{Am}$ sources still found application in calibration facilities, with a typical activity of $3.7 \cdot 10^{11} \mathrm{~Bq}$ (Table 1$)$.

The decay mode of ${ }^{60} \mathrm{Co}$ and ${ }^{137} \mathrm{Cs}$ is through beta emission, but their usefulness is related to the ensuing high energy gamma emission (1.333 and $1.173 \mathrm{MeV}$ for ${ }^{60} \mathrm{Co}$; $0.662 \mathrm{MeV}$ for $\left.{ }^{137} \mathrm{Cs}\right) .{ }^{192} \mathrm{Ir}$ has a more complex decay pattern $(95 \%$ through beta emission, $4.9 \%$ through electronic capture), and the main emission energies are $0.317,0.468$, and $0.604 \mathrm{MeV}$. On the contrary, ${ }^{238} \mathrm{Pu}$ and ${ }^{241} \mathrm{Am}$ are alpha emitters (the exact energy of the emitted particles depends on the decay scheme, and it is at about 5.5 MeV). However, ${ }^{241} \mathrm{Am}$ also emits a 59.5 $\mathrm{keV}$ gamma radiation $[14,15]$.

Table 1. Radionuclides

\begin{tabular}{ccc}
\hline Radionuclide & $\begin{array}{c}\text { Activity } \\
(\mathbf{B q})\end{array}$ & Practice \\
\hline${ }^{60} \mathrm{Co}$ & $1.50 \cdot 10^{14}$ & Teletherapy \\
\hline${ }^{137} \mathrm{Cs}$ & $1.90 \cdot 10^{13}$ & Teletherapy \\
\hline${ }^{192} \mathrm{Ir}$ & $3.70 \cdot 10^{12}$ & Industrial Radiography \\
\hline${ }^{238} \mathrm{Pu}$ & $1.00 \cdot 10^{13}$ & $\begin{array}{c}\text { Radioisotope Thermoelectric } \\
\text { Generators (RTGs) }\end{array}$ \\
\hline${ }^{241} \mathrm{Am}$ & $3.70 \cdot 10^{11}$ & Calibration facilities \\
\hline
\end{tabular}

\subsection{HOTSPOT Code}

HOTSPOT is a Health Physics code developed by the Lawrence Livermore National Laboratory (LLNL) and designed for short-term release duration. HOTSPOT uses a modified Gaussian plume model to simulate the release of radioactive material in the atmosphere. It is a fast and fieldportable set of software tools, useful in an emergency and unplanned situation.

In the present analysis, all simulations are performed with the version 3.1.2, running the "general explosion" module, and considering $10 \mathrm{~kg}$ of High Explosive (HE). It is a relatively high quantity, capable of totally pulverize the source shielding and casing, and able to damage a large area due to the conventional blast. In the present analysis, all the radioactive material is actually impacted in the release event, with a Respirable Fraction equal to 0.20 . Atmospheric conditions are supposed to be constant, with the wind blowing from the West $\left(270^{\circ}\right)$ at a speed equal to $3 \mathrm{~m} / \mathrm{s}$; the atmospheric stability class is $\mathrm{C}$, corresponding to sun low in the sky or cloudy weather. In the evaluation of the TED, the assumed solubility class is $\mathrm{M}$ (Moderate) and two different values of breathing rate are considered: an average of $1.2 \mathrm{~m}^{3} / \mathrm{h}$ for the population during the 4 days of exposure; an average of $2 \mathrm{~m}^{3} / \mathrm{h}$ for first responders, assumed to be on heavy work duties during rescue operations [16]. In all simulations, Ground Shine and Resuspension are included. According to Garland [17], the Resuspension Factor (RF) follows an inverse power law of time $\mathrm{t}$ (in days):

$$
\mathrm{RF}(\mathrm{t})=1.2 \cdot 10^{-6} \cdot \mathrm{t}^{-1}\left(\mathrm{~m}^{-1}\right)
$$

However, due to uncertainties in the early phases of the event, all simulations consider a constant value of RF equal to $10^{-5} \mathrm{~m}^{-1}$. Relevant HOTSPOT parameters are summarized in Table 2 .

Table 2. HOTSPOT parameters

\begin{tabular}{cc}
\hline Parameter & Value \\
\hline High Explosive weight & $10 \mathrm{~kg}(\mathrm{TNT})$ \\
\hline Solubility class & $\mathrm{M}$ \\
\hline Respirable Fraction & 0.20 \\
\hline Wind speed & $3 \mathrm{~m} / \mathrm{s}$ \\
\hline Wind direction & $270^{\circ}$ (wind from the West) \\
\hline Atmospheric stability class & $\mathrm{C}$ \\
\hline Resuspension Factor & $1.00 \cdot 10^{-5} \mathrm{~m}^{-1}$ \\
\hline
\end{tabular}

In HOTSPOT, Dose Conversion Factors are derived from the U.S. Federal Guidance Report 13 (FGR-13) [18], so that conversion coefficients and methodologies are taken from the ICRP Publications in the Series 60/70.

\subsection{Exposure scenarios of first responders and dose evaluation}

According to IAEA [19], first responders are "the first members of an emergency service to respond at the site of an emergency". The emergency services are the "local off-site response organizations that are generally available and that perform emergency response functions", and may include policemen, firefighters, rescue brigades, medical staff, and control teams for hazardous materials $[19,20]$.

Then, for the purposes of this work, only the first teams arrived in place are identified as "first responders", and, in particular, the exposure assessment will focus on firefighters and policemen. However, in general, "first responders" can be considered all the teams that manage "the first emergency" and therefore also the support ones.

In the case of Chemical, Biological, Radiological, Nuclear, and explosives (CBRNe) event, the intervention of the Fire Brigade takes place according to the information arriving in the operating room of the fire department. If the incident involves more than a certain number of victims and/or sensitive sites, a potential CBRNe alarm would be triggered. The teams sent to the scene would then be pre-alerted and would proceed with all the necessary precautions. The first 
teams arriving on site are made up of personnel with basic CBRNe training and are equipped with all "traditional" means of intervention (fire engines, first aid trucks), and a basic equipment that includes personal protective equipment for liquids and particulates (full-face mask with P3 filters [21] and self-contained breathing apparatus). Vehicles are normally equipped with at least two basic instruments: a (digital) radiation dosimeter and rate-meter and a multi gas detector (usually with sensors for flammable gases, $\mathrm{CO}, \mathrm{SO}_{2}, \mathrm{O}_{2}$ ).

The first teams to intervene could already be in place on average in 10-20 minutes, depending on traffic and distance. In any case, the team should already have indications on the nature of the event and the arrival in place should take place upwind.

Actually, the first teams on site do not have great operational capabilities, but rather they have the primary objective of identifying the CBRNe event and closing the area, then requiring specialist support. The staff at this stage could count on remote support from 2 nd or 3 rd level colleagues waiting for the specialized teams to arrive. Based on the information received or communicated by the first teams arrived on the spot, the rescue system is developed. It should be noted that the waiting times of the regional nuclei with specialized personnel could take some hours.

In case of an event involving the use of a dirty bomb, the actions of the first responders are therefore limited to closing the area, starting to separate any victims according to a reverse triage logic, i.e. a military triage type: those who can walk are rescued first and lastly the seriously injured.

Therefore, in the initial phase, a first rough triage is carried out by identifying an area upwind of the epicenter of the explosion in which to place the victims awaiting medical assistance. Then the first responders establish an evacuation zone of about $500 \mathrm{~m}$ radius around the center of the explosion (the radius depends on several variables, for example: the information collected, the context, the weather, the magnitude, etc.) and await the arrival of specialized personnel from the nearest regional command, who can assess radiation levels and outline contaminated areas.

These actions constitute a first intervention lasting even a few hours (on average, 2 hours can be considered), during which the team is exposed to radiation due to the dispersed radioactive material.

The dose received by first responders depends on the type of radionuclides involved. In the case of alpha emitters, the radiation would be difficult to detect immediately, so the first teams could arrive at the site of the explosion without adequate protection.

Two scenarios are considered, one that could resemble the presence of undetected alpha emitters, and one more suitable in the case of beta/gamma emitters, detected by the monitors from the start of the event.

In the first scenario, intervening responders are not aware of the danger and therefore they could not wear the mask when they arrive on site, as, for example, police officers. Effective dose is due to inhalation (and irradiation) of alpha emitters for one hour in the immediate vicinity of the explosion point and for another hour at about $500 \mathrm{~m}$ from the epicenter. On the contrary, in case they use the self-contained breathing apparatus, they have an autonomy of about 20 minutes after which it is necessary to change the cylinders, and therefore the need to wait the arrival of a support team.

In the second scenario, dose to first responders (alerted of the danger and therefore equipped with mask) is due to inhalation (with full face mask and filter) and irradiation from alpha, beta and gamma emitters for about 15 minutes in the immediate vicinity of the explosion point (possibly with selfcontained breathing apparatuses) and for an hour $500 \mathrm{~m}$ from the epicenter. In this case, emergency staff without personal protective equipment should stay out of the area nearer than $500 \mathrm{~m}$ to the epicenter.

\section{RESULTS}

HOTSPOT simulations of the dirty bomb explosion show that dose and contamination are largely variable, depending on the radionuclide and its activity. The initial assessment evaluates the TED received by the population (for an exposure duration of 4 days) and the surface contamination following the detonation. With regards to the values of $1 \mathrm{mSv}$, the highest downwind distance $(18 \mathrm{~km})$ is reached for ${ }^{238} \mathrm{Pu}$, covering an area of $2.5 \mathrm{~km}^{2}$. Moreover, the maximum downwind distance decreases from $5.9 \mathrm{~km}$ for ${ }^{60} \mathrm{Co}$ (the covered area is equal to $6.8 \mathrm{~km}^{2}$ ) to $2.8 \mathrm{~km}$ for ${ }^{241} \mathrm{Am}$ (the covered area is equal to $1.7 \mathrm{~km}^{2}$ ). A lower value, equal to 0.52 $\mathrm{km}$ and covering an area of $0.082 \mathrm{~km}^{2}$, is reached for ${ }^{192} \mathrm{Ir}$, whilst for ${ }^{137} \mathrm{Cs}$ the maximum downwind distance is $0.046 \mathrm{~km}$, covering an area of $3 \cdot 10^{-3} \mathrm{~km}^{2}$.

In the present study, the ground deposition following the explosion is evaluated at increasing downwind distances from the blast. As expected, the ground deposition strongly depends on the source activity, and the highest calculated value is due to ${ }^{60} \mathrm{Co}$, then (in decreasing order), ${ }^{137} \mathrm{Cs},{ }^{238} \mathrm{Pu},{ }^{192} \mathrm{Ir}$ and ${ }^{241} \mathrm{Am}$. An extract of the evaluation is shown in Table 3, namely at $0.050,0.100$, and $0.500 \mathrm{~km}$.

Table 3. Ground deposition $\left(\mathrm{kBq} / \mathrm{m}^{2}\right)$

\begin{tabular}{cccc}
\hline Radionuclide & $\mathbf{5 0} \mathbf{~ m}$ & $\begin{array}{c}\text { Distance } \\
\mathbf{1 0 0} \mathbf{~ m}\end{array}$ & $\mathbf{5 0 0} \mathbf{~ m}$ \\
\hline${ }^{60} \mathrm{Co}$ & $3.4 \cdot 10^{6}$ & $1.3 \cdot 10^{6}$ & $1.6 \cdot 10^{5}$ \\
\hline${ }^{137} \mathrm{Cs}$ & $4.3 \cdot 10^{5}$ & $1.6 \cdot 10^{5}$ & $2.0 \cdot 10^{4}$ \\
\hline${ }^{192} \mathrm{Ir}$ & $8.4 \cdot 10^{4}$ & $3.1 \cdot 10^{4}$ & $4.0 \cdot 10^{3}$ \\
\hline${ }^{238} \mathrm{Pu}$ & $2.3 \cdot 10^{5}$ & $8.4 \cdot 10^{4}$ & $1.1 \cdot 10^{4}$ \\
\hline${ }^{241} \mathrm{Am}$ & $8.4 \cdot 10^{3}$ & $3.1 \cdot 10^{3}$ & $4.0 \cdot 10^{2}$ \\
\hline
\end{tabular}

A second set of evaluations is performed through the HOTSPOT code, with the aim of calculating the dose received by first responders, intervening after the plume passage. Avoiding the plume passage, the TED contributions are due to ground shine (external irradiation) and to resuspension (internal contamination following inhalation). Values obtained through simulations are used to calculate the dose received by the emergency personnel during operational activities.

In detail, the dose is calculated considering the exposure starting one hour after the blast, with a duration of one hour. Due to the short time postulated for the first response, it is assumed that surface contamination and resuspension are constant (after the plume passage), and the Resuspension Factor (RF) is conservatively set at $10^{-5} \mathrm{~m}^{-1}$. For the same reason, no weather or washout corrections are applied. Even if the Fire Brigade should be informed about the wind direction (so that an upwind intervention can be planned), the present analysis considers a conservative, worst case scenario, in which firefighters (or police officers, for example) approach the blast location downwind.

The dose shows high values of TED at short distances from the blast. At $50 \mathrm{~m}$, the resulting dose can be high for the 
extremely radiotoxic ${ }^{238} \mathrm{Pu}$, and for ${ }^{60} \mathrm{Co}$ (Table 4 ).

Table 4. Calculated TED (Sv) for 1 hour stay at selected downwind distances

\begin{tabular}{cccc}
\hline Radionuclide & $\mathbf{5 0 ~} \mathbf{~ m}$ & $\begin{array}{c}\text { Distance } \\
\mathbf{1 0 0} \mathbf{~ m}\end{array}$ & $\mathbf{5 0 0} \mathbf{~ m}$ \\
\hline${ }^{60} \mathrm{Co}$ & $2.9 \cdot 10^{-2}$ & $1.1 \cdot 10^{-2}$ & $1.4 \cdot 10^{-3}$ \\
\hline${ }^{137} \mathrm{Cs}$ & $9.3 \cdot 10^{-4}$ & $3.4 \cdot 10^{-4}$ & $4.4 \cdot 10^{-5}$ \\
\hline${ }^{192} \mathrm{Ir}$ & $2.4 \cdot 10^{-4}$ & $8.9 \cdot 10^{-5}$ & $1.2 \cdot 10^{-5}$ \\
\hline${ }^{238} \mathrm{Pu}$ & $2.1 \cdot 10^{-1}$ & $7.7 \cdot 10^{-2}$ & $1.0 \cdot 10^{-2}$ \\
\hline${ }^{241} \mathrm{Am}$ & $7.0 \cdot 10^{-3}$ & $2.6 \cdot 10^{-3}$ & $3.3 \cdot 10^{-4}$ \\
\hline
\end{tabular}

As expected, the evaluation of dose contributions shows that ground shine is dominant over the resuspension for gamma emitters: $98 \%\left({ }^{60} \mathrm{Co}\right), 91 \%\left({ }^{137} \mathrm{Cs}\right)$, and $96 \%\left({ }^{192} \mathrm{Ir}\right)$; on the contrary, ground shine is negligible for alpha emitters $\left({ }^{241} \mathrm{Am}\right.$ and $\left.{ }^{238} \mathrm{Pu}\right)$.

In the first scenario, it is postulated that first responders spend one hour in the proximity of the blast point (at a distance of $50 \mathrm{~m}$ ), and an additional hour at $500 \mathrm{~m}$, without respiratory protections. Due to the high level of damage caused by the conventional bomb, the distance of $50 \mathrm{~m}$ is considered representative for early operations. Moreover, it avoids a probable overestimation of the contamination at shorter distances in the HOTSPOT dispersion model [22].

The resulting TED is high for ${ }^{238} \mathrm{Pu}\left(2.2 \cdot 10^{-1} \mathrm{~Sv}\right)$ and for ${ }^{60} \mathrm{Co}\left(3.0 \cdot 10^{-2} \mathrm{~Sv}\right)$. The TED decreases for ${ }^{241} \mathrm{Am}$ (about 7 $\mathrm{mSv}$ ), ${ }^{137} \mathrm{Cs}$, and ${ }^{192} \mathrm{Ir}$ (in both cases, below $1 \mathrm{mSv}$ ).

Figure 1 shows the ${ }^{238} \mathrm{Pu}$ isodose lines passing at $50 \mathrm{~m}$ $\left(2.1 \cdot 10^{-1} \mathrm{~Sv}\right)$ and at $500 \mathrm{~m}\left(1.0 \cdot 10^{-2} \mathrm{~Sv}\right)$ downwind, assuming 1 hour of continuous stay at the selected locations.

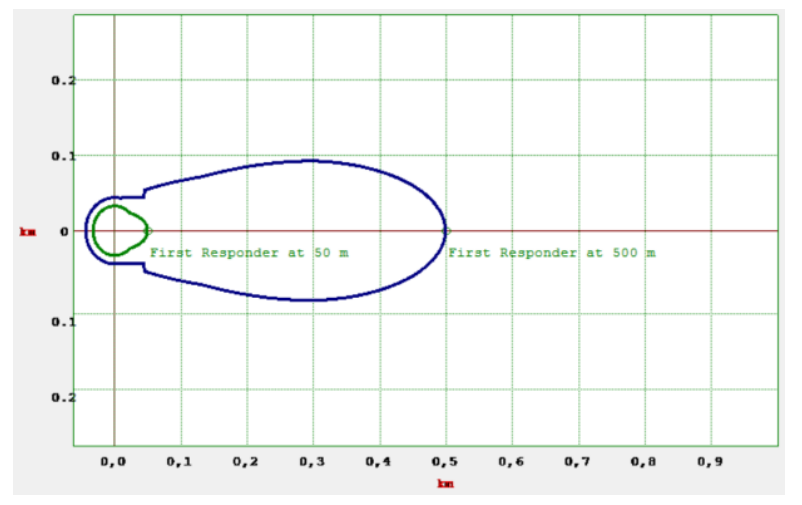

Figure 1. ${ }^{238} \mathrm{Pu}$ isodose lines passing at $50 \mathrm{~m}\left(2.1 \cdot 10^{-1} \mathrm{~Sv}\right)$ and at $500 \mathrm{~m}\left(1.0 \cdot 10^{-2} \mathrm{~Sv}\right)$ downwind, assuming a stay time of 1 hour

As stated, it is a worst-case scenario. In case of the presence of high gamma emitter ${ }^{60} \mathrm{Co}$, it is very unlikely that the high dose rate is not detected, even with rough detectors. However, the alpha emitter ${ }^{238} \mathrm{Pu}$ needs a more specialized instrumentation to be detected.

In the second scenario, first responders spend 15 minutes in the proximity of the blast point $(50 \mathrm{~m})$, and an additional hour at $500 \mathrm{~m}$ from it, resulting in a TED accordingly decreased. In this scenario, it is also assumed that first responders, when operating at short distance $(50 \mathrm{~m})$, are equipped with full face mask respirators, able to reduce the radionuclide inhalation by a factor of $10^{3}$ [23]. Consequently, the TED due to alpha emitters $\left({ }^{241} \mathrm{Am}\right.$ and $\left.{ }^{238} \mathrm{Pu}\right)$ is greatly reduced, according to the decrease in the inhaled activity. On the contrary, regarding gamma emitters, the dose rate from the ground shine is the same as before, and it is the predominant component of the resulting TED (Table 5).

Table 5. Calculated TED (Sv) for $15 \mathrm{~min}$ of stay at $50 \mathrm{~m}$ from the blast point and $1 \mathrm{~h}$ at $500 \mathrm{~m}$ (exposure scenario \# 2)

\begin{tabular}{cc}
\hline \multirow{2}{*}{ Radionuclide } & $\begin{array}{c}\text { TED (Sv) } \mathbf{1 5} \text { min at } \mathbf{5 0} \text { m and } 1 \mathrm{~h} \text { at 500 } \\
\text { m }\end{array}$ \\
\hline${ }^{60} \mathrm{Co}$ & $8.4 \cdot 10^{-3}$ \\
\hline${ }^{137} \mathrm{Cs}$ & $2.6 \cdot 10^{-4}$ \\
\hline${ }^{192} \mathrm{Ir}$ & $7.0 \cdot 10^{-5}$ \\
\hline${ }^{238} \mathrm{Pu}$ & $1.0 \cdot 10^{-2}$ \\
\hline${ }^{241} \mathrm{Am}$ & $3.3 \cdot 10^{-4}$ \\
\hline
\end{tabular}

It is of noteworthy importance that, for alpha emitters ${ }^{238} \mathrm{Pu}$ and ${ }^{241} \mathrm{Am}$, about $99 \%$ of the TED is due to inhalation at 500 $\mathrm{m}$, where protective respiratory equipment is not in use.

In addition, it cannot be excluded a malicious use of a mixture of radionuclides. If the detonated source contains all the 5 radionuclides, the TED is calculated as the sum of the 5 individual contributions, according to the additivity of the effective dose. Therefore, in the second scenario (first responders spend 15 minutes at $50 \mathrm{~m}$, and 1 hour at $500 \mathrm{~m}$ from the blast) the resulting TED is equal to $1.9 \cdot 10^{-2} \mathrm{~Sv}$. This value is clearly dictated by ${ }^{238} \mathrm{Pu}$ and ${ }^{60} \mathrm{Co}$ contributions.

A final calculation is produced according to the dose as a function of the time spent at selected distances, with the aim to evaluate the number of hours needed to reach a selected value of dose, equal to $1 \mathrm{mSv}$ and $20 \mathrm{mSv}$ of TED. For both levels of dose, the calculation is performed considering persons without respirators and with full-face respirators, able to reduce the inhalation of radioactive particles resuspended from the ground by a factor $10^{3}$. An extract of the results is presented in Table 6 (TED $1 \mathrm{mSv}$, without respirators), Table 7 (TED $1 \mathrm{mSv}$, with respirators), Tables 8 (TED $20 \mathrm{mSv}$, without respirators) and Table 9 (TED $20 \mathrm{mSv}$, with respirators).

Table 6. Calculated stay time (h) to reach $1 \mathrm{mSv}$ without respirators according to the downwind distance

\begin{tabular}{cccccc}
\hline Radionuclide & $\mathbf{1 0 0} \mathbf{~ m}$ & $\mathbf{2 0 0} \mathbf{~ m}$ & $\begin{array}{c}\text { Dist. } \\
\mathbf{3 0 0} \mathbf{~ m}\end{array}$ & $\mathbf{5 0 0} \mathbf{~ m}$ & $\mathbf{1} \mathbf{~ k m}$ \\
\hline${ }^{60} \mathrm{Co}$ & 0.1 & 0.2 & 0.3 & 0.7 & 2.6 \\
\hline${ }^{137} \mathrm{Cs}$ & 2.9 & 6.3 & 10.1 & 22.5 & 80.6 \\
\hline${ }^{192} \mathrm{Ir}$ & 11.2 & 24.3 & 38.7 & 86.8 & 309 \\
\hline${ }^{238} \mathrm{Pu}$ & 0.0 & 0.0 & 0.0 & 0.1 & 0.4 \\
\hline${ }^{241} \mathrm{Am}$ & 0.4 & 0.8 & 1.3 & 3.0 & 10.7 \\
\hline
\end{tabular}

Table 7. Calculated stay time (h) to reach $1 \mathrm{mSv}$ with respirators according to the downwind distance

\begin{tabular}{cccccc}
\hline Radionuclide & $\mathbf{1 0 0 ~} \mathbf{m}$ & $\mathbf{2 0 0} \mathbf{~ m}$ & $\begin{array}{c}\text { Dist. } \\
\mathbf{3 0 0} \mathbf{~ m}\end{array}$ & $\mathbf{5 0 0} \mathbf{~ m}$ & $\mathbf{1} \mathbf{~ k m}$ \\
\hline${ }^{60} \mathrm{Co}$ & 0.1 & 0.2 & 0.3 & 0.7 & 2.7 \\
\hline${ }^{137} \mathrm{Cs}$ & 3.2 & 6.9 & 11.0 & 24.8 & 88.5 \\
\hline${ }^{192} \mathrm{Ir}$ & 11.6 & 25.2 & 40.2 & 90.1 & 321 \\
\hline${ }^{238} \mathrm{Pu}$ & 12.9 & 28.0 & 44.7 & 100 & 358 \\
\hline${ }^{241} \mathrm{Am}$ & 354 & 768 & 1229 & 2753 & 9797 \\
\hline
\end{tabular}

Comparing Table 6 with Table 7, and Table 8 with Table 9, it is worth to mention that the number of hours spent in the area to reach the selected values shows a negligible difference between wearing or not the full-face respirators, if the 
radioactive material is a gamma emitter: in this case, the TED is predominately due to the external contribution, with a much lower contribution from inhalation.

Table 8. Calculated stay time (h) to reach $20 \mathrm{mSv}$ without respirators according to the downwind distance

\begin{tabular}{cccccc}
\hline Radionuclide & $\mathbf{1 0 0} \mathbf{~ m}$ & $\mathbf{2 0 0} \mathbf{~ m}$ & $\begin{array}{c}\text { Dist. } \\
\mathbf{3 0 0} \mathbf{~ m}\end{array}$ & $\mathbf{5 0 0} \mathbf{~ m}$ & $\mathbf{1} \mathbf{~ k m}$ \\
\hline${ }^{60} \mathrm{Co}$ & 1.9 & 4.1 & 6.5 & 14.6 & 52.0 \\
\hline${ }^{137} \mathrm{Cs}$ & 58.0 & 126 & 201 & 451 & 1612 \\
\hline${ }^{192} \mathrm{Ir}$ & 223 & 486 & 774 & 1737 & 6179 \\
\hline${ }^{238} \mathrm{Pu}$ & 0.3 & 0.6 & 0.9 & 2.0 & 7.2 \\
\hline${ }^{241} \mathrm{Am}$ & 7.8 & 16.8 & 26.9 & 60.2 & 214 \\
\hline
\end{tabular}

Table 9. Calculated stay time (h) to reach $20 \mathrm{mSv}$ with respirators according to the downwind distance $(>5 \mathrm{y}$ indicates more than 5 years)

\begin{tabular}{cccccc}
\hline Radionuclide & $\mathbf{1 0 0} \mathbf{~ m}$ & $\mathbf{2 0 0} \mathbf{~ m}$ & $\begin{array}{c}\text { Dist. } \\
\mathbf{3 0 0} \mathbf{~ m}\end{array}$ & $\mathbf{5 0 0} \mathbf{~ m}$ & $\mathbf{1} \mathbf{~ k m}$ \\
\hline${ }^{60} \mathrm{Co}$ & 1.9 & 4.2 & 6.7 & 14.9 & 53.3 \\
\hline${ }^{137} \mathrm{Cs}$ & 63.7 & 139 & 221 & 495 & 1770 \\
\hline${ }^{192} \mathrm{Ir}$ & 232 & 504 & 803 & 1802 & 6410 \\
\hline${ }^{238} \mathrm{Pu}$ & 258 & 561 & 895 & 2005 & 7152 \\
\hline${ }^{241} \mathrm{Am}$ & 7085 & 15361 & 24570 & $>5 \mathrm{y}$ & $>5 \mathrm{y}$ \\
\hline
\end{tabular}

On the contrary, for alpha emitters in general, and for ${ }^{238} \mathrm{Pu}$ and ${ }^{241} \mathrm{Am}$ in the present analysis, avoiding the inhalation of resuspended radionuclides proves to be very effective in reducing the dose and, conversely, in increasing the permissible stay time.

In the case that a mixture of radionuclides is detonated, the stay time is dominated by the radionuclide with the highest dose rate $\left({ }^{60} \mathrm{Co}\right.$ or ${ }^{238} \mathrm{Pu}$, if respirators are in use or not, respectively), whereas remaining radionuclides do not significantly contribute. For example, at $500 \mathrm{~m}$ and without respirators, the stay time to reach the $20 \mathrm{mSv}$ value is 14.6 hours for ${ }^{60} \mathrm{Co}$ alone, and 14.3 hours for the mixture of the 5 radionuclides.

For the two radionuclides with the largest impact $\left({ }^{60} \mathrm{Co}\right.$ and ${ }^{238} \mathrm{Pu}$ ), the present study also analyses the trend of the hours spent (h) to reach the $20 \mathrm{mSv}$ value as a function of the distance (d), in the range from 0.100 to $2000 \mathrm{~km}$. The results show that, if protective respirators are not in use, the stay time increases with the distance, according to a polynomial function of order 2 (Figure 2).

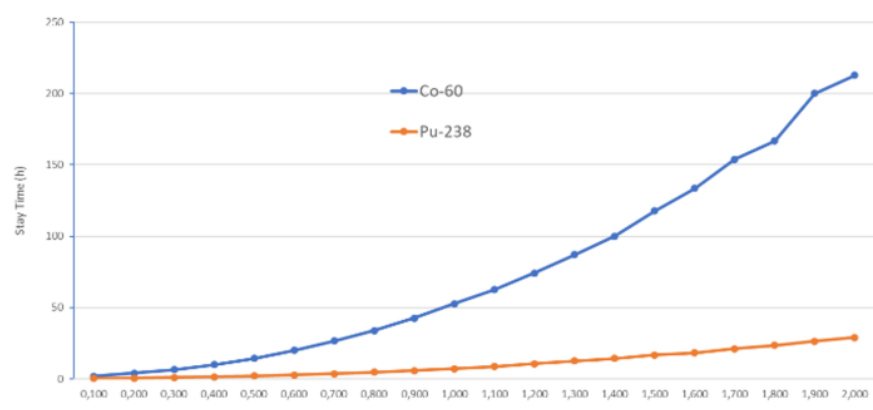

Figure 2. Trend of the stay time (h) versus distance $(\mathrm{km})$

For ${ }^{60} \mathrm{Co}$, the trend is well fitted by the function.

$$
h=57.4 \mathrm{~d}^{2}-1.0134 \mathrm{~d}+4.2844\left(\mathrm{R}^{2}=0.9987\right)
$$

For ${ }^{238} \mathrm{Pu}$, the trend is well fitted by the function.

$$
h=7.38 \mathrm{~d}^{2}-0.0378 \mathrm{~d}+0.3085\left(\mathrm{R}^{2}=0.9997\right)
$$

\section{CONCLUSIONS}

The HOTSPOT simulations show that the dose due to the plume passage is relatively low, with the notable exception of ${ }^{238} \mathrm{Pu}$ (a TED of $20 \mathrm{mSv}$ can be reached at a maximum downwind distance of $3.4 \mathrm{~km}$ ). However, casualties and damage caused by the blast itself are probably the main effect of a dirty bomb detonation. The TED for first responders is strongly dependent on the radionuclide and on the time spent in the area. However, in the proximity of the blast, where the contamination is higher, first responders can be exposed to high level of TED. Considering that "first responders" is a broad category, the present analysis focuses on police officers and firefighters.

From the radiation protection point of view, police officers are considered members of the general public, so that a legal dose limit of $1 \mathrm{mSv}$ per year applies. On the contrary, firefighters can be classified as radiation workers, with a legal limit equal to $20 \mathrm{mSv}$. A restricted number of specialized members in the National Firefighters Corps is designed as "emergency workers". Accordingly, in special circumstances the maximum dose is not set, maintaining that all reasonable efforts should be made to keep effective doses below $100 \mathrm{mSv}$.

In the first exposure scenario considered, when first responders are not aware of the danger, for example in case of the presence of undetected alpha emitters, doses due to ${ }^{238} \mathrm{Pu}$ are up to $220 \mathrm{mSv}$. Then, the possibility of a scenario like this implies that first responders should approach an uncharacterized blast only if equipped with self-contained breathing apparatus or, at least, full-face mask with P3 filters.

In the second exposure scenario, when the presence of gamma emitters can allow first responders to be aware of the risk, calculated doses show that personnel classified as category A workers should approach the area near the blast equipped with full-face mask, while can operate outside the inner circle for a calculated stay time of about 15 hours (without exceeding the legal limit of $20 \mathrm{mSv}$ ). On the other hand, first responders who are non-classified radiation workers, such as police officers, can approach the area near the blast only if equipped with full-face mask, and can operate outside this area for a calculated stay time of less than 1 hour (before exceeding the legal limit of $1 \mathrm{mSv}$ ). In conclusion, the possibility of the presence of alpha emitters in a dirty bomb of the type here considered implies that first responders approaching the point of the explosion should always wear a full-face mask, and in any case non classified personnel should operate no longer than 1 hour within the blast area of $500 \mathrm{~m}$ radius.

According to the performed simulations, the contamination is determined by wind speed and direction, and by the atmospheric stability. Following the wind direction, the contaminated area depicts an elliptic-like shape. Consequently, interdiction or evacuation in a circular area, centered at the blast point, is not necessarily the most efficient choice. In addition, a $500 \mathrm{~m}$ radius can be exceedingly problematic, for example in a city center,

Moreover, the visual observation of the initial plume can give information about the direction of contamination, and it can be useful for first responders approaching the area. 
It is important to note that, for alpha emitters, the use of a self-contained breathing apparatus proves to be very effective in strongly reducing the dose. In fact, the high dose caused by internal contamination from alpha emitters is reduced to negligible levels if the inhalation of resuspended radionuclides is avoided. For gamma emitters, the highest contribution is due to the external exposure, so that avoiding the internal contribution is of very limited effect on the dose. In that case, intervention and clean-up activities must be carefully planned, protecting emergency workers through shielding (for example, placed at the working locations), or limiting the individual intervention time through appropriate shifts.

It is plausible that several limitations may have influenced the results: atmospheric and weather conditions can only be postulated, and the same is true for radionuclides and their activity. In the present analysis each radionuclide is evaluated separately, but the use of a mixture of radionuclides cannot be excluded. However, a major advantage of the TED stands in its additivity. The effective dose calculated for each radionuclide can be added, and the sum is the TED due to the mixture of radionuclides. It is possible that the simulated surface concentration (and the resulting TED) in the proximity of the blast is not accurately assessed by a gaussian diffusion model. Moreover, the time spent at the selected distances (10 $\mathrm{m}$ and $500 \mathrm{~m}$ ) is grossly approximated, and it can vary according to the situation encountered. However, the present analysis clearly shows that ground contamination near the detonation point can result in high doses. If gamma emitters are involved, the dominant contribution is due to the external irradiation, but at the same time the contamination can be easier to detect, keeping first responders and public at a safety distance. If alpha emitters are involved, the resulting contamination can be much more difficult to detect. However, the use of respirators can greatly reduce the inhaled activity, lowering the TED to negligible levels.

Moreover, after the first intervention, the residual contamination must be carefully evaluated and properly communicated to the general public and to residing persons, with the aim of protect people and avoid psychological health effects due to the general fear of radiation. Trust in local and intervening authority will prove to be very important for the return to normality.

\section{REFERENCES}

[1] Ferguson, C.D., Potter, W.C. (2004). The four faces of nuclear terrorism. Center for nonproliferation studies.

[2] Ring, J.P. (2004). Radiation risks and dirty bombs. Health Physics, 86(S2): S42-S47. https://doi.org/10.1097/00004032-200402001-00013

[3] Vogel, H. (2007). Rays as weapons. European Journal of Radiology, 63(2): $167-77$ https://doi.org/10.1016/j.ejrad.2007.04.028

[4] Rosoff, H., Von Winterfeldt, D. (2007). A risk and economic analysis of dirty bomb attacks on the ports of Los Angeles and Long Beach. Risk Analysis, 27(3): 533546. https://doi.org/10.1111/j.1539-6924.2007.00908.x

[5] Saint Yves, T.L.A., Cabral, P.A.M., Brum, T., Rother, F.C., Alves, P.F.P.M., Lauria, D.C., de Andrade, E.R. (2012). Terrorist Radiological Dispersive Device (RDD) Scenario and Cancer Risk Assessment. Human and Ecological Risk Assessment: An International Journal, 18(5):

971-983 https://doi.org/10.1080/10807039.2012.707926

[6] Musolino, S.V., Harper, F.T. (2006). Emergency response guidance for the first 48 hours after the outdoor detonation of an explosive radiological dispersal device. Health Physics, 90(4): 377-85. https://doi.org/10.1097/01.HP.0000196111.16261.ed

[7] Musolino, S.V., Harper, F.T., Buddemeier, B., Brown, M., Schlueck, R. (2013). Updated emergency response guidance for the first $48 \mathrm{~h}$ after the outdoor detonation of an explosive radiological dispersal device. Health Physics, 105(1): 65-73. https://doi.org/10.1097/HP.0b013e31828a8fb1

[8] Ingram, R.J. (2018). Emergency response to radiological releases: have we communicated effectively to the first responder communities to prepare them to safely manage these incidents? Health Physics, 114(2): 208-213. https://doi.org/10.1097/HP.0000000000000757

[9] Homann, S.G., Aluzzi F. (2020). HOTSPOT Health Physics Codes Version 3.1.2 User's Guide. Lawrence Livermore National Laboratory.

[10] International Commission on Radiological Protection (2007). The 2007 Recommendations of the International Commission on Radiological Protection. ICRP Publication 103. Ann. ICRP, 37(2-4).

[11] Biancotto, S., Malizia, A., Pinto, M., Contessa, G.M., Coniglio, A., D’Arienzo, M. (2020). Analysis of a dirty bomb attack in a large metropolitan area: simulate the dispersion of radioactive materials. Journal of Instrumentation. 15(2). https://doi.org/10.1088/17480221/15/02/P02019

[12] Martellini, M., Malizia, A. (Eds.) (2017). Cyber and Chemical, Biological, Radiological, Nuclear, Explosives Challenges. Threats and Counter Efforts. Springer International Publishing.

[13] International Atomic Energy Agency. (2005). Categorization of radioactive sources. IAEA Safety Standards Series No. RS-G-1.9.

[14] Delacroix, D., Guerre, J.P., Leblanc, P., Hickman, C. (2002). Radionuclide and radiation protection data handbook. Radiation Protection Dosimetry, 98(1): 1-168. https://doi.org/10.1093/oxfordjournals.rpd.a006705

[15] Martin, J.E. (2013). Physics for Radiation Protection. Wiley-VCH Verlag \& Co.

[16] The Royal Society. (2001). The health hazards of depleted uranium munitions. The Royal Society, London.

[17] Garland, J.A. (1982) Resuspension of particulate material from grass. Experimental programme 19791980. No. AERE-R-10106. UKAEA Atomic Energy Research Establishment.

[18] Environmental Protection Agency. (1999). Cancer Risk Coefficients for Environmental Exposure to Radionuclides. Federal Guidance Report No. 13. U.S. EPA.

[19] International Atomic Energy Agency. (2019). IAEA Safety Glossary: 2018 Edition, IAEA, Vienna.

[20] Barquinero, J.F., Fattibene, P., Chumak, V. et al. (2021). Lessons from past radiation accidents: Critical review of methods addressed to individual dose assessment of potentially exposed people and integration with medical assessment. Environment International, 146: 106175. https://doi.org/10.1016/j.envint.2020.106175

[21] German Institute for Standardisation. (1988). DIN 31814: 1988.

[22] Purves, M., Parkes, D. (2016). Validation of the DIFFAL, 
HPAC and HOTSPOT dispersion models using the fullscale radiological dispersal device (FSRDD) field trials witness plate deposition dataset. Health Physics, 110(5): 481-490.

[23] U.S. Nuclear Regulatory Commission. Standards for
Protection Against Radiation (1999). Code of Federal Regulations. Washington, D.C. U.S. Government Printing Office; Title 10, Part 20, Washington, DC: USNRC. 